\title{
Sociodemographic Risk Factors and Correlates of Dementia in Older Malaysians
}

\author{
Tengku Aizan Hamid ${ }^{a}$ Saroja Krishnaswamy ${ }^{b}$ Siti Suhailah Abdullah ${ }^{a}$ \\ Yadollah Abolfathi Momtaz ${ }^{\mathrm{a}}$ \\ ${ }^{a}$ Institute of Gerontology, Universiti Putra Malaysia, Serdang Selangor, Malaysia; ${ }^{b}$ Clinical Epidemiology, \\ University of Adelaide, Adelaide, S.A., Australia
}

\section{Key Words}

Prevalence $\cdot$ Dementia Older Malaysians .

Sociodemographic factors

\begin{abstract}
Objective: The rapid expansion of the aged population in Malaysia is expected to greatly increase the number of persons with dementia in the country. However, data on dementia prevalence at the national level is lacking, and little is known about the sociodemographic risk factors and correlates of dementia. This paper describes a nationwide study of dementia prevalence and its sociodemographic risk factors and health correlates among older Malaysians. Methods: In the nationwide study, the Mental Health and Quality of Life of Older Malaysians, AGECAT-GMS was used to diagnose dementia in a nationally representative sample of 2,980 persons aged 60 and above. Results: The prevalence rate of dementia was $14.3 \%$. Higher dementia prevalences were found in oldest age (26.3\%), women (19.7\%), no formal education (24.1\%), Bumiputeras (32.2\%), unmarried (19.4\%), unemployed (31.3\%) and very poor on self-rated health (33.3\%). Multivariate logistic regression analyses showed that older age, female gender, no formal education, ethnicity and very poor self-rated health were independent risk factors and correlates of dementia. Conclusions: Relatively higher prev-
\end{abstract}

(C) 2011 S. Karger AG, Basel

$1420-8008 / 10 / 0306-0533 \$ 26.00 / 0$

Fax +41613061234

E-Mail karger@karger.ch

www.karger.com
Accessible online at: www.karger.com/dem alence rates of dementia in older Malaysians were accounted for by greater proportions without education, Malay and Bumiputera ethnicity, and other unknown factors which should be further investigated.

Copyright $\odot 2011$ S. Karger AG, Basel

\section{Introduction}

The numbers of people worldwide with Alzheimer's disease and other dementias are projected to double every 20 years to 81 million by 2040 . The rate of increase in the number of persons with dementia is 3-4 times higher in developing countries than in developed countries [1]. Hence, despite the fact that dementia prevalence are higher in developed countries, by $2040,71 \%$ of the world's total number of persons with dementia will be living in developing nations, the majority in China and other Asia Pacific countries. This huge and rapidly growing population of persons with dementia will place a heavy demand on health care and social services in developing countries.

The total population of Malaysia is currently 28.25 million (2010) and comprises 4.7\% [2] who are aged 65 and above; however, Malaysia, in the 3rd stage of demographic transition, is 4th in the world in terms of the projected percentage growth of older persons aged 65 years and over

Tengku Aizan Hamid, Associate Professor and Director

Institute of Gerontology

Universiti Putra Malaysia

UPM, Serdang Selangor (Malaysia)

Tel. +6038947 2750, Fax +6038947 2738, E-Mail aizan@ putra.upm.edu.my 
predicted for the years 2008 to 2040 [3]. This expansion of the aged population is expected to increase the number dementia cases in the country. However, there is a lack of data on the prevalence of dementia at the national level, and little is known about the sociodemographic risk factors and health correlates of dementia in the country.

An earlier study in 1997 [4] among urban older Malays living in the capital city of Kuala Lumpur, using a 2-stage procedure (screening and diagnostic interview using GMS-AGECAT and clinician's diagnosis), reported a dementia prevalence of $6 \%$ among those aged 65 years and above, and a $12 \%$ prevalence among those aged 75 years. However, the findings from this study are limited in its geographical coverage (to only urban Kuala Lumpur) and ethnic coverage (only ethnic Malays), and little is known about the sociodemographic risk factors and health correlates of dementia in Malaysia.

Age is an established risk factor for dementia and the prevalence increases with age [5-8]. Women are noted in many studies as having higher rates of dementia $[4,5$, 7, 9].

Numerous studies have shown that more years of education are associated with a lower risk of developing dementia $[10,11]$. Epidemiological studies have consistently demonstrated ethnic and geographical differences in rates of dementia. Compared to countries in North America and Europe, lower rates of dementia are reported in countries in Asia and Africa, particularly China, Japan, Singapore, India and Nigeria [1]. Ethnic differences among African, Japanese and Caucasian Americans $[12,13]$ and among Chinese, Malay and Indian elderly in Singapore [8, $14,15]$ have also been reported. Malays and Bumiputeras (indigenous people of Sabah and Sarawak) make up 65\% of the multiethnic population of Malaysia, and Chinese comprise $26 \%$, Indians $8 \%$ and other $1 \%$, but ethnic comparison of the risks of dementia has not been investigated.

The present paper describes a nationwide study of dementia prevalence among older Malaysians, and examines the sociodemographic risk factors and health correlates of dementia.

\section{Methods}

Survey

The Mental Health and Quality of Life of Older Malaysians project was 1 of 3 research projects under a program (Mental Health and Quality of Life Program) funded by the Ministry of Science, Technology and Innovation through the Intensified Research in Priority Areas Program under the Eighth Malaysia Plan. The objectives of the project were to investigate the prevalence of mental problems, identify the relationships between mental and quality of life of older Malaysians and to investigate the relationships between stress, coping resources and mental status of older Malaysians. This pioneering research project on the mental health of the elderly in the country, headed by the corresponding author, started in September 2002 and ended in October 2006.

The field work for the Mental Health and Quality of Life of Older Malaysians lasted a year starting in May 2004 to December 2005, and was conducted in all 13 Malaysian states and the Federal Territory of Kuala Lumpur. The area samples of older (ages $60+$ ) community-dwelling persons were identified with assistance from the Department of Statistics Malaysia. Multistage sampling was used to achieve an appropriate nationwide representation of the older population for the survey, which was proportionately distributed across the states. Informed consent was obtained from the respondents before the interview was conducted. Trained enumerators conducted face-to-face interviews with 1 family member for every household in randomly selected enumeration blocks. A selection grid was used to achieve parity in the sample's sex distribution. The final sample size was 2,980 persons. The response rate was $88 \%$.

The Geriatric Mental State (GMS) B3 version was used in the study to assess the mental health status of the respondents. The enumerators were trained by an experienced investigator from India who was a member of the 10/66 research group. Doorto-door surveys using hand-held PDAs and hard-copy questionnaires were used in the data collection. Data from the GMS-B3 was entered into the AGECAT software program which generated diagnoses for organicity, depression and anxiety disorders on 6 levels of confidence (0-5), with levels 3 and greater representing likely cases warranting professional intervention. Copeland, Dewy and Saunders [31] noted that AGECAT diagnosis has satisfactory reliability and can be used for epidemiologic studies even without professional interviewers. Moreover, Prince at al. [16] validated the GMS-AGECAT among a poorly educated older population in developing countries and noted the shortened B3 community version of GMS provided a more valid assessment of dementia than GMS-A3. The GMS-B3 version was therefore used in our study.

\section{Statistical Analysis}

Dependent Variable

The dependent variable was dementia. For this analysis, cases that met the AGECAT-GMS diagnostic algorithm for a diagnosis of organic disorder were analyzed as the dependent variable. A $\chi^{2}$ test for dichotomous variables and Student's t tests for continuous variables were used to compare dementia and nondementia groups. Binomial logistic regression was used to estimate the odds ratios of associations yielding point estimates with $95 \%$ confidence intervals in multivariate analyses with covariate adjustment for potential confounding variables.

\section{Independent Variables}

Sociodemographic correlates and risk factors used in this analysis included age, marital status, sex, place of residence, employment status, educational attainment and ethnicity. Age was categorized into 3 age groups: $60-69$ years, $70-79$ years and 80 years and over. The 60-69-year group was used as the reference category. Sex was dummy-coded as male $=0$ (reference category) and female $=1$. Ethnicity included Malays, Bumiputeras (indigenous people), Chinese, Indians and other. Ethnic Chinese is used 
as the reference group. Marital status was dichotomized as married $=1$, unmarried $=0$ (single, divorced, widowed or separated; reference category). Educational attainment included no formal education (reference category), primary education and secondary or tertiary education. Place of residence was dichotomized to urban $=1$ and rural $=0$ (reference category). Employment status was categorized as employed $=1$ and unemployed $=0$ (reference category). Self-rated health was measured using the single question 'How would you describe your health status?', with possible answers ranging from very good (4) to very poor (1); very poor health status was used as the reference. Self-reported stroke and hypertension were dichotomized as yes $=1$ and no $=0$ (reference category). The level of statistical significance tests was set at $\mathrm{p}<0.05$ with 2-tailed distribution. Data were analyzed using SPSS software for Windows (SPSS Inc., Chicago, Ill., USA).

\section{Results}

The sample consisted of 2,980 community-dwelling older Malaysians comprising 1,503 women and 1,477 men, with an average age of 70.5 years $(S D=7.22)$. The overall prevalence of dementia was $14.3 \%$ (table 1). The prevalence rates showed a clearly increasing trend by age groups, doubling every 10 years, from $9.5 \%$ in the 60-69 age group, to $26.3 \%$ in those aged 80 and above.

Women showed a higher prevalence rate $(24 \%)$ compared to men (8.8\%). Among dementia cases, women (69\%) outnumbered (2:1) men (30.6\%; table 2$)$. Unmarried respondents $(19.4 \%)$ had almost twice the prevalence rate of dementia as married respondents (10.2\%), and among dementia cases, unmarried (widowed, divorced, single) persons $(60 \%)$ outnumbered married respondents (40\%). The prevalence rate of dementia was almost 2 times higher in rural populations (18.6\%) than in urban populations $(10.9 \%)$, with slightly more rural residents than urban residents among dementia cases.

Among the 3 health indices (self-reported hypertension, stroke and self-rated health status), significantly higher prevalence rates were noted among respondents with stroke (26.5\%), compared to those without stroke (14.5\%). The frequency of stroke among dementia cases was $3.5 \%$, compared to $1.5 \%$ in nondementia respondents.

The prevalence of dementia was strongly correlated with self-reported health, increasing from $5.0 \%$ among those in very good health to $33.3 \%$ among those who reported very poor health. Among dementia cases, $8.8 \%$ reported very poor health.

There was a considerably higher prevalence of dementia among respondents who were unemployed (31.3\%) compared to those who were employed (4.5\%). Among dementia cases, about $80 \%$ were unemployed.

Sociodemographic Risk Factors of

Dementia in Older Malaysians
Table 1. Prevalence of dementia by health and sociodemographic factors

\begin{tabular}{|c|c|c|c|c|}
\hline Variable/category & $\begin{array}{l}\text { Total } \\
\mathrm{n}\end{array}$ & $\begin{array}{l}\text { Cases } \\
\mathrm{n}\end{array}$ & $\begin{array}{l}\text { Preva- } \\
\text { lence, \% }\end{array}$ & $95 \% \mathrm{CI}$ \\
\hline \multicolumn{5}{|l|}{ Age } \\
\hline $60-69$ & 1,519 & 145 & 9.5 & $8.2-11.1$ \\
\hline $70-79$ & 1,049 & 179 & 17.1 & $14.9-19.5$ \\
\hline $80+$ & 350 & 92 & 26.3 & $21.9-31.1$ \\
\hline \multicolumn{5}{|l|}{ Sex } \\
\hline Male & 1,456 & 128 & 8.8 & $7.4-10.4$ \\
\hline Female & 1,469 & 290 & 19.7 & $17.8-21.8$ \\
\hline \multicolumn{5}{|l|}{ Education } \\
\hline No formal education & 1,309 & 316 & 24.1 & $21.9-26.5$ \\
\hline Primary & 1,291 & 88 & 6.8 & $5.6-8.3$ \\
\hline Secondary/tertiary & 281 & 7 & 2.5 & $1.2-5.1$ \\
\hline \multicolumn{5}{|l|}{ Ethnicity } \\
\hline Malay & 1,725 & 256 & 14.8 & $13.2-16.6$ \\
\hline Bumiputera & 320 & 103 & 32.2 & $27.3-37.5$ \\
\hline Chinese & 700 & 44 & 6.3 & $4.7-8.3$ \\
\hline Indian & 139 & 8 & 5.8 & $2.9-10.9$ \\
\hline Other & 41 & 7 & 17.1 & $8.5-31.3$ \\
\hline \multicolumn{5}{|l|}{ Place of residence } \\
\hline Rural & 1,290 & 240 & 18.6 & $16.6-20.8$ \\
\hline Urban & 1,635 & 178 & 10.9 & $9.4-12.5$ \\
\hline \multicolumn{5}{|l|}{ Marital status } \\
\hline Married & 1,630 & 167 & 10.2 & $8.9-11.8$ \\
\hline Unmarried & 1,290 & 250 & 19.4 & $17.3-21.6$ \\
\hline \multicolumn{5}{|l|}{ Employment } \\
\hline Employed & 1,639 & 73 & 4.5 & $3.6-5.6$ \\
\hline Unemployed & 951 & 298 & 31.3 & $28.5-34.3$ \\
\hline \multicolumn{5}{|l|}{ Hypertension } \\
\hline Yes & 892 & 126 & 14.1 & $12.0-16.6$ \\
\hline No & 1,887 & 284 & 15.1 & $13.5-16.7$ \\
\hline \multicolumn{5}{|l|}{ Stroke } \\
\hline Yes & 49 & 13 & 26.5 & $16.2-40.3$ \\
\hline No & 2,729 & 397 & 14.5 & $13.3-15.9$ \\
\hline \multicolumn{5}{|l|}{ Self-rated health } \\
\hline Very poor & 108 & 36 & 33.3 & $25.2-42.7$ \\
\hline Poor & 948 & 182 & 19.2 & $16.8-21.8$ \\
\hline Good & 1,481 & 178 & 12.0 & $10.5-13.8$ \\
\hline Very good & 239 & 12 & 5.0 & $2.9-8.6$ \\
\hline
\end{tabular}

The risk of dementia was considerably higher among those with no formal education (24.1\%), compared to those with primary $(6.8 \%)$ or secondary or tertiary education (2.5\%). A large majority of dementia cases were those who had no formal education (77\%), in contrast to those without dementia (40\%).

Among the ethnic groups, the Bumiputera (indigenous ethnic group of Sabah and Sawarak) recorded by far the highest prevalence rate of dementia (32.1\%) compared to Malays (14.8\%), Chinese (6.3\%) or Indians (5.8\%). Bumiputera ethnicity represented $20 \%$ of the cases of de- 
Table 2. Distribution of population according to dementia status $(\mathrm{n}=2,980)$

\begin{tabular}{|c|c|c|c|c|c|}
\hline \multirow{2}{*}{$\begin{array}{l}\text { Variable/ } \\
\text { category }\end{array}$} & \multicolumn{2}{|c|}{ No dementia } & \multicolumn{2}{|c|}{ Dementia } & \multirow[t]{2}{*}{$x^{2}$} \\
\hline & $\mathrm{n}$ & $\%$ & $\mathrm{n}$ & $\%$ & \\
\hline \multicolumn{6}{|l|}{ Age } \\
\hline 60-69 & 1,374 & 54.9 & 145 & 34.9 & \multirow[t]{3}{*}{$75.77^{* *}$} \\
\hline $70-79$ & 870 & 34.8 & 179 & 43.0 & \\
\hline $80+$ & 258 & 10.3 & 92 & 22.1 & \\
\hline \multicolumn{6}{|l|}{ Marital status } \\
\hline Married & 1,463 & 58.4 & 167 & 40.0 & \multirow[t]{2}{*}{$49.08^{* *}$} \\
\hline Not married & 1,040 & 41.6 & 250 & 60.0 & \\
\hline \multicolumn{6}{|l|}{ Sex } \\
\hline Male & 1,328 & 53.0 & 128 & 30.6 & \multirow[t]{2}{*}{$71.58^{* *}$} \\
\hline Female & 1,179 & 47.0 & 290 & 69.4 & \\
\hline \multicolumn{6}{|l|}{ Place of residence } \\
\hline Rural & 1,050 & 41.9 & 240 & 57.4 & \multirow[t]{2}{*}{$35.06^{* *}$} \\
\hline Urban & 1,457 & 58.1 & 178 & 42.6 & \\
\hline \multicolumn{6}{|l|}{ Hypertension } \\
\hline Yes & 766 & 32.3 & 126 & 30.7 & \multirow[t]{2}{*}{0.41} \\
\hline No & 1,603 & 67.7 & 284 & 69.3 & \\
\hline \multicolumn{6}{|l|}{ Stroke } \\
\hline Yes & 36 & 1.5 & 13 & 3.2 & \multirow[t]{2}{*}{$5.49^{*}$} \\
\hline No & 2,332 & 98.5 & 397 & 96.8 & \\
\hline \multicolumn{6}{|l|}{ Self-rated health } \\
\hline Very poor & 72 & 3.0 & 36 & 8.8 & \multirow[t]{4}{*}{$71.56^{* *}$} \\
\hline Poor & 766 & 32.3 & 182 & 44.6 & \\
\hline Good & 1,303 & 55.0 & 178 & 43.6 & \\
\hline Very Good & 227 & 9.6 & 12 & 2.9 & \\
\hline \multicolumn{6}{|l|}{ Employment status } \\
\hline Employed & 1,566 & 70.6 & 73 & 19.7 & \multirow[t]{2}{*}{$14.98^{* *}$} \\
\hline Unemployed & 653 & 29.4 & 298 & 80.3 & \\
\hline \multicolumn{6}{|l|}{ Ethnicity } \\
\hline Malay & 1,469 & 58.6 & 256 & 61.2 & \multirow[t]{5}{*}{$129.25^{* *}$} \\
\hline Bumiputera & 217 & 8.7 & 103 & 24.6 & \\
\hline Chinese & 656 & 26.2 & 44 & 10.5 & \\
\hline Indian & 131 & 5.2 & 8 & 1.9 & \\
\hline Other & 34 & 1.4 & 7 & 1.7 & \\
\hline \multicolumn{6}{|l|}{ Educational attainment } \\
\hline No formal education & 993 & 40.2 & 316 & 76.9 & \multirow[t]{3}{*}{$194.79^{* *}$} \\
\hline Primary education & 1,203 & 48.7 & 88 & 21.4 & \\
\hline $\begin{array}{l}\text { Secondary and } \\
\text { tertiary education }\end{array}$ & 274 & 11.1 & 7 & 1.7 & \\
\hline
\end{tabular}

mentia, whereas its representation among nondementia cases was only $9 \%$, which was similar to that in the general population.

Binary logistic regression was used to estimate adjusted odds ratios of association with dementia for each sociodemographic and health variable in multivariate analyses that controlled mutually for differences in age, gender, education and health characteristics (table 3). Marital
Table 3. Results of multivariate binary logistic regression of odds of association with dementia

\begin{tabular}{|c|c|c|c|}
\hline \multirow[t]{2}{*}{ Variable } & \multirow[t]{2}{*}{ OR } & \multicolumn{2}{|c|}{$95 \% \mathrm{CI}$} \\
\hline & & lower & upper \\
\hline \multicolumn{4}{|c|}{ Age (reference group: $60-69$ years of age) } \\
\hline $70-79$ & $1.48^{*}$ & 1.12 & 1.97 \\
\hline $80+$ & $2.15^{* *}$ & 1.49 & 3.12 \\
\hline Female (vs. male) & $1.61^{*}$ & 1.21 & 2.21 \\
\hline \multicolumn{4}{|c|}{ Education (reference group: no formal education) } \\
\hline Primary education & $0.32^{* *}$ & 0.24 & 0.44 \\
\hline Secondary/tertiary education & $0.16^{* *}$ & 0.06 & 0.42 \\
\hline Urban residence (vs. rural) & 0.91 & 0.69 & 1.18 \\
\hline Married (vs. not married) & 0.83 & 0.62 & 1.1 \\
\hline Employed (vs. unemployed) & 1.02 & 0.73 & 1.43 \\
\hline \multicolumn{4}{|c|}{ Self-rated health (reference group: very poor) } \\
\hline Poor & 0.68 & 0.4 & 1.16 \\
\hline Good & $0.48^{* *}$ & 0.28 & 0.81 \\
\hline Very good & $0.22^{*}$ & 0.09 & 0.55 \\
\hline Hypertension & 0.76 & 0.57 & 1 \\
\hline Stroke & 1.46 & 0.67 & 3.15 \\
\hline \multicolumn{4}{|c|}{ Ethnicity (reference group: Chinese) } \\
\hline Malay & $2.19^{* * *}$ & 1.44 & 3.31 \\
\hline Bumiputera & $5.06^{* *}$ & 3.14 & 8.15 \\
\hline Indian & 1.10 & 0.43 & 2.82 \\
\hline Other & $2.69^{*}$ & 1.00 & 7.22 \\
\hline
\end{tabular}

${ }^{*} \mathrm{p}<0.05,{ }^{* *} \mathrm{p}<0.01,{ }^{* * *} \mathrm{p}<0.001$. Hosmer and Lemeshow test $\left(\chi^{2}=5.86, \mathrm{p}=662\right)$. Nagelkerke $\mathrm{R}^{2}=0.23$.

and employment status and urban/rural residence were not independently associated with dementia after accounting for the confounding influence of age, sex, education, ethnicity and self-rated health. The significant independent variables associated with dementia in the multivariate model included older age (the odds of dementia for those aged 70-79 years was 1.5 times, and for those aged 80 years and over was about twice that of older persons aged 60-69) and sex (1.5 times more in women). Compared to no formal education, primary level education was associated with a $72 \%$ less likelihood of dementia, and higher education with an $86 \%$ less likelihood of dementia. Malays, 'other' and Bumiputeras reported high chances of getting dementia compared to Chinese. Malays and 'other' ethnic groups were twice as likely and Bumiputera were 5 times more likely to show dementia compared to Chinese. Others reported slightly higher chances than Malays. For Indians, the likelihood of dementia was not significantly different. Increasing levels of better perceived self-rated health was associated with a lower likelihood (36\%) of dementia. 


\section{Discussion}

In this population-based study of 2,980 communitydwelling older persons 60 years and over, the prevalence rate of dementia in Malaysia was estimated at $14.3 \%$ overall. This estimated dementia prevalence is higher than most reports from other countries in the Asia-Pacific region, and may be explained in part by differences in sociodemographic characteristics, particularly education and ethnicity.

Multivariate analyses revealed that advancing age, female sex, level of education, ethnicity, and self-rated health were independent risk factors and correlates of dementia. These findings are in good accord with a large number of studies that have reported sociodemographic risk factors for dementia.

The higher prevalence of dementia among females found in this study was in agreement with that reported in an earlier study [4] conducted on older Malays in an urban settlement in Kuala Lumpur, which noted that females were 4 times more likely to show dementia. Similar gender differences were also reported in many studies [5, $7,9]$ after adjusting for age. The higher risk of dementia for women may be explained by a life of accumulated social disadvantages in current cohorts of older Malaysians which were greater for women, i.e. a lack of educational opportunities in early life which severely hindered access to employment and personal development. Lower educational attainment and less complex occupational activities have been found to be associated with cognitive decline and dementia risks $[17,18]$.

Bivariate and multivariate analyses showed that education was strongly associated with dementia and by far the most important factor contributing to elevating the prevalence of dementia in the Malaysian population. A large body of evidence consistently supports the strong association of low educational attainment with cognitive impairment and dementia $[19,20]$. Low educational attainment is one indicator of socioeconomic disadvantage that may begin in early life and is associated with increased risk of dementia [17, 18]. Conversely, a high level of educational attainment is linked to better socioeconomic status and access to health care, conferring through its effect on functional health literacy more favorable risk profiles such as vascular diseases and lifestyle factors. Mental and intellectually challenging activities involved in educational and complex mental activities is recognized as having a powerful role in maintaining or enhancing brain reserve and is thus protective against the risk of dementia in old age [10].

Sociodemographic Risk Factors of Dementia in Older Malaysians
The estimated prevalence among Malays in this study (15\%) was higher than that reported by Krishnaswamy et al. [4] in the earlier survey of Malays (6\%), who were urban dwellers in Kuala Lumpur and generally had more years of education. In the present study, the large proportion of older persons with no formal education $(45.4 \%)$ or primary education $(44.8 \%)$ was a major contributor to the higher overall prevalence, which exceeds those of most other Asia-Pacific countries. Another main contributor to the higher dementia prevalence was the higher representation by the Malays (59\%) and $\mathrm{Bu}$ miputeras (11\%), which both have higher rates of dementia (15 and 32\%) than the Chinese (6.3\%) and Indians $(5.8 \%)$.

Almost the same ethnic difference in dementia prevalence was reported by studies in the multiethnic population in Singapore, a neighboring country which also has Chinese, Malay and Indian ethnicities. Using the same diagnostic instrument, GMS-AGECAT $[8,15]$, a higher dementia prevalence was observed for Malays $(9.4 \%)$ than Chinese (4.2\%), but the prevalence of dementia among Indians was also high (8.8\%). The respondents in the Singapore sample (60 years and above) were similar in age (mean age 69.4), but the proportion of older persons with no formal education was lower (35\%) and Chinese were the majority (75\%), whereas Malays comprised $15 \%$. In another study of older Singaporeans [14], similar ethnic differentials in dementia rates were observed among Malays (1.6\%), Chinese (1.2\%) and Indians (1.9\%), although it should be noted that prevalence estimates were considerably lower because of higher screening thresholds and more stringent clinical diagnoses.

In this study, results from multivariate analyses showed that ethnic differences in dementia prevalence, with ethnic Chinese showing lower prevalence of dementia compared to Malays, were not explained by differences in gender, age or education. Other probable explanations include cardiometabolic, cerebrovascular and lifestyle risks, as well as genetic factors. In our study, a higher prevalence of stroke reported within the last 12 months prior to the survey was seen among Malays (2.2\%) and Bumiputeras (2.5\%), compared to $0.4 \%$ for Chinese and $1.4 \%$ for Indians. However, we found that self-reports of hypertension among Malays (30\%) were not higher compared to Chinese (33.1\%) and Indians (35.5\%), but the validity of this information is in doubt. The Institute of Public Health [21] noted the overall prevalence of hypertension for Malaysian residents aged 30 years and over was $42.6 \%$, and ethnic Malays of both gender recorded $45.3 \%$, which was higher than both the Chinese (40.6\%)

Dement Geriatr Cogn Disord 2010;30:533-539 
and Indians (40.0.\%), but comparable to the Bumiputeras in Sabah (45.2\%) and Sarawak (42.4\%).

In terms of diabetes mellitus, the prevalence rates for people in the age range of 50-59 were $20-24 \%$ and the highest prevalence rate was among the 60-64 age group with $26.1 \%$. This rate is more than double the national prevalence of $11.6 \%$. Diabetes prevalence for Malaysians aged 18 years and above was highest among Indians (19.9\%), followed by Malays (11.9\%), Chinese (11.4\%) and the Bumiputeras of Sabah and Sarawak (6.0\%). Suriah et al. [22] studied healthy postmenopausal women and noted ethnic differences in BMI and physical activity levels. Malay females recorded significantly higher BMI than female Chinese and were also less active compared to Chinese. Moreover, $62.5 \%$ of female Chinese exercise regularly compared to only $46.5 \%$ of female Malays. Rosnah et al. [23] also noted significant differences in BMI between Malays and non-Malays, favoring the Malays. Shahar et al. [24] conducted a multidimensional assessment of nutritional and health status of rural Malay older persons and noted problems with both undernutrition and overnutrition, and also recorded a high prevalence of dyslipidemia. Comparable results on dyslipidemia among other ethnic groups is not available.

Distinct ethnic differences in the frequency of the APOE-4 allele, the gene most strongly associated with the risk of Alzheimer's disease, have been reported. This gene is least common in Chinese (13\%) in comparison to Malays (20\%) or Indians (24\%) [25].

Part of the ethnic differences in dementia prevalence could possibly be attributed to cultural practices that influence the onset and detection of dementia. For example, the phenomenon of 'nyanyuk' is similar to dotage and is accepted among the Malays. 'Nyanyuk' has several connotations relating to situations or behaviors. It involves feeble mindedness, being slightly crazy, and showing physical and mental weakness. The behavior manifestation of 'nyanyuk' is inappropriate infantile behavior in adults or is considered as second childhood [26].

Results of bivariate and multivariate analyses also revealed a significant correlation between self-rated health and dementia. It is well documented that self-rated health significantly predicts mortality and functional status in old age, but its association with dementia has not been adequately studied. Yip et al. [27] in their study found that self-report of poor health was associated with increased risk of dementia. This association is noteworthy because there is strong evidence from meta-analysis that self-rated health is an independent predictor of nursing home placement [28]. Self-rated health is correlated with underlying cognitive and/or functional impairment, and is associated with lack of support and assistance in daily living.

There are limitations to this study. The accuracy of self-reports of hypertension and stroke are questionable, given the fact that undiagnosed hypertension was likely to be common, and no blood pressure measurements were made in the survey. The failure to demonstrate a significant association between self-reports of hypertension and stroke in this study is therefore not surprising. The link between blood pressure and stroke with dementia is well documented in many studies $[13,29,30]$. Other cardiovascular, metabolic and lifestyle risk factors, including leisure time activities that are known risk factors for dementia, were not examined. These factors need to be further investigated in future studies.

Malaysia is reflective of most Asia-Pacific countries where increasing life expectancies with older women outliving men will result in more women among the 'old-old' and among persons with dementia. By association, the disproportionate large numbers of nonmarried (mostly widowed) women, and unemployed persons among persons with dementia have important implications for the need of care and the availability of care options. Special attention would need to be paid to the disproportionately large numbers of Malay and Bumiputera persons with dementia. Further research is needed to elucidate the reasons behind ethnic differences in dementia prevalence and to develop intervention strategies to prevent or delay the onset of dementia.

\section{Acknowledgements}

The researchers are in debt to the older persons and fieldworkers who participated in this study. Without the tireless effort from the fieldworkers, the nationwide survey would not have been possible. The researchers also acknowledge the Ministry of Science, Technology and Innovation for supporting the project (IRPA 0602-04-0461PR0031). The authors contributed in the following ways: T.A.H. did the literature search and wrote the first draft and final version of paper; S.K. had access to the AGECAT program and made comments on the paper; S.S.A. managed and supervised the nationwide data collection; and Y.A.M. did the literature search and ran the analyses. 


\section{References}

$>1$ Wimo A, Winblad B, Aguero-Torres H, von Strauss E: The magnitude of dementia occurrence in the world. Alzheimer Dis Assoc Disord 2003;17:63-67.

2 Department of Statistics Malaysia. Key statistics. 2010. http://www.statistics.gov.my (accessed Aug. 13, 2010).

3 Kinsella K, Wan HE: Aging World 2008. US Census Bureau, International Population Reports, P95/09-1. Washington, US Government Printing Office, 2009

4 Krishnaswamy S, Kadir K, Ali RA, Sidi H, Mathews S: Prevalence of dementia among Malaysia in an urban settlement in Malaysia. Neurol J Southeast Asia 1997;2:159-162.

5 Gussekloo J, Heeren TJ, Izaks GJ, Lighthart GJ, Rooijmans HGM: A community based study of the incidence of dementia in subjects aged 85 years and over. J Neurol Neurosurg Psychiatry 1995;59:507-510.

6 Ghubash R, El-Rufaie O, Zoubeidi T, AlShboul QM, Sabri SM: Profile of mental disorders among the elderly United Arab Emirates population: sociodemographic correlates. Int J Geriatr Psychiatry 2004;19: 344-351.

7 Kim JM, Stewart R, Prince M, Shin IS, Yoon JS: Diagnosing dementia in a developing nation: an evaluation of the GMS-AGECAT algorithm in an older Korean population. Int J Geriatr Psychiatry 2003; 18:331-336.

$>8$ Kua EH: Dementia in elderly Malays-preliminary findings of a community survey. Singapore Med J 1993;34:26-28.

$>9$ Lobo A, Saz P, Marcos G, et al: The ZARADEMP Project on the incidence, prevalence and risk factors of dementia (and depression) in the elderly community. II. Methods and first results. Eur J Psychiatry 2005 19:40-54.

10 Valenzuela MJ, Sachdev P: Brain reserve and dementia: a systematic review. Psychol Med 2006;36:441-454.
11 Mortimer JA, Snowdon DA, Markesbery WR: Head circumference, education and risk of dementia: findings from the Nun Study. J Clin Exp Neuropsych 2003;25:671679.

12 Sink KM, Covinsky KE, Newcomer R, Yaffe $\mathrm{K}$ : Ethnic differences in the prevalence and pattern of dementia-related behaviors. J Am Geriatr Soc 2004;52:1277-1283.

13 Shadlen MF, Larson EB, Gibbons LE, et al: Ethnicity and cognitive performance among older African Americans, Japanese Americans, and Caucasians: the role of education. J Am Geriatr Soc 2001;49:1371-1378.

14 Sahadevan S, Saw SM, Gao W, et al: Ethnic differences in Singapore's dementia prevalence: the Stroke, Parkinson's Disease, Epilepsy, and Dementia in Singapore Study. J Am Geriatr Soc 2008;56:2061-2068.

15 Ng TP, Leong T, Chiam PC, Kua EH: Ethnic variations in dementia: the contributions of cardiovascular, psychosocial and neuropsychological factors. Dement Geriatr Cogn Disord 2010;10:131-138.

16 Prince M, Acosta D, Chiu H, et al: Effects of education and culture on the validity of the Geriatric Mental State and its AGECAT algorithm. Br J Psychiatry 2004;185:429-436.

17 Whalley LJ, Dick FD, McNeill G: A lifecourse approach to the aetiology of late-onset dementias. Lancet Neurol 2006;5:87-96.

18 Ngandu T, Von Strauss E, Helkala EL, et al: Education and dementia: what lies behind the association? Neurology 2007;69:14421450 .

19 Katzman R: Education and the prevalence of dementia and Alzheimer's disease. Neurology 1993;43:13-20.

20 Caamano-Isorna F, Corral M, Montes-Martínez A, Takkouche B: Education and dementia: a meta-analytic study. Neuroepidemiology 2006;26:226-232.

21 Institute of Public Health: The Third National Health and Morbidity Survey (NHMS III) 2006 vol 1 and 2. Putrajaya, Ministry of Health Malaysia, 2008.
22 Suriah AR, Chee WSS, Zaitun Y, Chan SP: Vitamin D status among postmenopausal Malaysian women. Asia Pac J Clin Nutr 2004;13:255-260.

23 Rosnah MY, Mohd Rizal H, Sharifah Norazizan SAR: Anthropometry Dimensions of Older Malaysians: Comparison of Age, Gender and Ethnicity. Asian Soc Sci 2009;5:133140

24 Shahar S, Ibrahim Z, Fatah ARA, et al: A multidimensional assessment of nutritional and health status of rural elderly Malays. Asia Pac J Clin Nutr 2007;16:346-352.

25 Hallman DM, Boerwinkle E, Saha N, et al: The apoliporpotein E polymorphism: a comparison of allele frequencies and effects in nine populations. Am J Human Genet 1991; 4:338-349.

26 Dewan Bahasa dan Pustaka. Nyanyuk. http://prpm.dbp.gov.my/Search.aspx?k= nyanyuk (accessed Aug. 10, 2010).

27 Yip AG, Brayne C, Matthews FE: Risk factors for incident dementia in England and Wales: the Medical Research Council Cognitive Function and Ageing Study. A populationbased nested case-control study. Age Ageing 2006;35:154-160.

28 Luppa M, Luck T, Weyerer S, Konig HH, Brahler E, Riedel-Heller SG: Prediction of institutionalization in the elderly. A systematic review. Age Ageing 2010;39:31-38.

29 Leys D, Henon H, Pasquier MC: Post stroke dementia. Lancet Neurol 2005;4:752-759.

30 Zhu L, Fratiglioni L, Guo Z, Aguero-Torres $\mathrm{H}$, Winblad B, Viitanen M: Association of stroke with dementia, cognitive impairment, and functional disability in the very old: a population based study. Stroke 1998;29: 2094-2099.

31 Copeland J, Dewey M, Saunders P: The epidemiology of dementia: GMS-AGECAT studies of prevalence and incidence, including studies in progress. Eur Arch Psychiatry Clin Neurosci 1991;240:212-217. 